\title{
Teorias do desenvolvimento e a cooperação internacional*1
}

Luciano Barbosa de Lima²

\section{Resumo}

Este trabalho tem como objetivo abordar de forma didática o tema do desenvolvimento e sua evolução desse conceito, tendo como base as principais tendências teóricas, entre elas as teorias tradicionais da modernização, estruturalista, neomarxista, da dependência, neoclássica, assim como uma introdução às teorias alternativas do desenvolvimento como, a teoria do Desenvolvimento Humano, Gênero e Desenvolvimento, Desenvolvimento multidimensional, Desenvolvimento Endógeno, Ecodesenvolvimento e o Pós-desenvolvimento. O estudo é concluído com observações à aplicação desse conceito no âmbito das atividades de cooperação internacional.

Palavras-chave: Desenvolvimento. Teorias do desenvolvimento. Cooperação internacional. Relações internacionais. Desenvolvimento econômico. Políticas de desenvolvimento.

\section{Introdução}

Cada vez ouvimos falar mais no termo "desenvolvimento", comumente usado pelas diferentes áreas das ciências sociais e referindo geralmente como o

* Recebido em 11.09.2009

Aprovado em 04.11.2009

1 Adaptação revisada de capítulo da tese de Mestrado em Cooperação Internacional e Gestão de Projetos de Desenvolvimento da Universidade de Málaga (Espanha) defendida por Luciano Barbosa de Lima em julho de 2008 e tendo como orientador o professor Dr. Pablo Podadera Rivera. Durante os estudos do citado mestrado Luciano Barbosa de Lima foi bolsista do programa Becas MAEC-AECID entre 2006 e 2008.

2 Doutorando em Economia, Gestão e Controle de Entidades e Políticas Públicas pela Universidade de Granada, Mestre em Cooperação Internacional e Gestão de Projetos de Desenvolvimento pela Universidade de Málaga, Bacharel em Relações Internacionais pelo UniCEUB. e-mail: luciano.balima@gmail.com 
avanço esperado, aquele objetivo esperado pelas políticas e projetos almejados pelos diversos atores internacionais.

No entanto, apesar da intensificação da aplicação desse conceito no âmbito internacional e o incremento de políticas dirigidas a combater a pobreza, observamos que muitos países do Terceiro Mundo continuam sofrendo de pobreza econômica, condições humanas precárias, desigualdade social, instabilidade política, relações de dependência externa, degradação ambiental, conflitos étnico-religiosos, entre outros.

O conceito de desenvolvimento, por si só, está intrinsecamente influenciado por diversos interesses e perspectivas, tornando importante conhecer e entender esse conceito, sua evolução e as novas tendências teóricas que tendem a orientar as políticas dos países e das relações entre estes. Portanto, este estudo tem como objetivo introduzir respostas aos questionamentos: como surge o conceito de desenvolvimento? Qual a sua evolução e como tem sido usado pelos atores internacionais no âmbito das relações internacionais?

Inserimos-nos em um contexto de constante necessidade de revisão de ações de desenvolvimento e das próprias relações internacionais, uma vez que "this situation of inadequate development theories and ineffective development policies implies that there is a need for serious rethinking in the field" (HAQUE, 1999, p. 12).

A essas ações de desenvolvimento nos referimos aos âmbitos internacionais como locais, considerando que com a globalização e as novas tecnologias de comunicação e informação (TICs), esses âmbitos já não podem ser desconectados.

As relações internacionais estão intrinsecamente relacionadas com à ideia de desenvolvimento, uma vez que as relações de poder e submissão se referem fundamentalmente nas dependências econômicas, sociais e políticas advindas de suas condições de dar e receber e, portanto, suas teorias sofrem as mesmas interferências internacionais no cenário de jogo de poderes.

Antes de começarmos a trabalhar com as correntes teóricas, devemos ressaltar que qualquer atividade de agrupação de autores em uma corrente teórica tem 
como objetivo a mera sistematização do seu estudo; no entanto, não deve reduzir nem simplificar nossa visão das ideias e proposta de cada autor.

Este trabalho tem como objetivo não concluir ou generalizar a discussão sobre o termo de desenvolvimento e sua aplicação na cooperação internacional, mas levantar conceitos básicos e teorias fundamentais que possam introduzir estudos sobre o tema.

O presente documento inicia-se com uma recuperação da evolução histórica do conceito de desenvolvimento; são apresentadas algumas das principais correntes teóricas tradicionais, a citar: teoria da modernização, teoria da dependência, teoria estruturalista, teoria neomarxista e teoria neoclássica, críticas às teorias tradicionais e novas tendências como a teoria do desenvolvimento humano, gênero e desenvolvimento e outras teorias alternativas como o desenvolvimento multidimensional, Endodesenvolvimento, Ecodesenvolvimento e o Pós-desenvolvimento. O escrito é concluído com observações quanto à teoria do desenvolvimento e à aplicação no âmbito da cooperação internacional, este último sendo considerado como um importante instrumento das relações internacionais no que tange a implementar ações dirigidas a populações mais pobres do mundo e mitigar a pobreza.

O termo cooperação internacional será tratado neste estudo de forma ampla e especialmente abrangendo o conceito de cooperação para o desenvolvimento, buscando ampliar conceitos como a cooperação técnica ou cooperação financeira.

\section{Desenvolvimento e cooperação}

\subsection{Evolução histórica}

Depois da Segunda Guerra Mundial, ainda não se tinha claro o conceito de desenvolvimento e as instituições do Sistema de Bretton Woods regiam as relações internacionais. Naquele tempo, o GATT utilizava a ideia de "países menos desenvolvidos" como uma forma de se referir ao subdesenvolvimento como uma mera etapa a qual se deveria traspassar. 
Nos anos 50 e 60 se fortalecem os diálogos Norte-Sul e o aspecto específico de subdesenvolvimento, entre as conquistas dos países do Sul naquele momento estão a criação da Conferência das Nações Unidas sobre Comércio e Desenvolvimento (UNCTAD), posteriormente institucionalizada, e a Organização das Nações Unidas para o Desenvolvimento Industrial (UNIDO).

Anúncio pelos Estados Unidos da América do fim do padrão ouro-dólar no início dos anos 70 criou um contexto de insegurança e desconfiança no mundo decorrente da grave crise econômica e a primeira crise do petróleo (baixa e alta repentina do preço do petróleo). Esse contexto aprofundou os problemas dos países menos desenvolvidos pela tendência dos países de deixar o livre comércio generalizado (Free Trade) e promover a formação de regionalismos.

Por estes motivos se considera a década de 80 como a década perdida para os países em desenvolvimento, visto que pouco se alcançou nas negociações no âmbito internacional, especialmente provocados por: 1) Falta de compromisso político dos países do Norte, que além do mais afirmavam que o problema do subdesenvolvimento era prioritariamente interno e que os países deveriam corrigir suas debilidades domésticas; 2) negligência por parte dos países do Sul em quanto à distribuição de poder mundial e no reconhecimento dos problemas internos do subdesenvolvimento e pobreza (LIMA, 2005).

Na década de 90 o tema do desenvolvimento reaparece com a Conferência das Nações Unidas sobre Meio Ambiente e Desenvolvimento (Rio-92) e a Cúpula das Américas em 1994. Em 2000 celebrou a Cúpula do Milênio, na qual se definiram os Objetivos de Desenvolvimento do Milênio (ODM), assim fortalecendo a rede de instituições de desenvolvimento e a convergência de esforços e ações.

Muitas outras reuniões, cúpulas e declarações foram desenvolvidas posteriormente. No entanto, apesar dessas evoluções nas negociações do desenvolvimento a nível internacional, poderia dizer que é um tema ainda novo e carece de evolução para lograr as políticas de desenvolvimento sejam realmente eficazes e seus instrumentos coerente com as realidade local, uma vez que alguns instru- 
mentos de cooperação ainda não tomam em conta as diferenças culturais, étnicos, religiosos, níveis de desenvolvimento etc.

\section{Fundamentos teóricos do desenvolvimento}

Apesar de existirem várias teorias e uma constante releitura delas, me fixarei neste artigo nas principais teorias de desenvolvimento e suas evoluções. Poderíamos citar como principais: a teoria da modernização, a teoria da dependência, a teoria estruturalista, a teoria neomarxista e a teoria neoclássica, assim como tendências novas como a teoria do desenvolvimento humano, a perspectiva de gênero e outras teorias alternativas do desenvolvimento, as quais serão detalhadas neste artigo.

\subsection{Teorias tradicionais do desenvolvimento}

As teorias tradicionais do desenvolvimento são uma agrupação metodológica que se refere a um conjunto de teorias que prezam sua perspectiva de análise a um âmbito predominantemente ou meramente econômico do desenvolvimento. Tem sido as teorias mais usadas ainda nos dias de hoje pelos governos e organismos internacionais nas suas políticas.

Essas teorias que formam parte dessa classificação seriam as da modernização, a estruturalista, a neomarxista, a da dependência e a neoclássica, as quais detalharemos nos tópicos seguintes.

\subsubsection{Teoria da modernização}

As distintas Teorias da Modernização têm em comum a ideia de que o objetivo do desenvolvimento é a reprodução da experiência dos países desenvolvidos, implementando uma réplica de seu processo de industrialização. Podemos citar como principais autores dessa corrente Samuel Huntington e Walt Rostow, os quais 
consideram o desenvolvimento como um processo linear e que todos devem passar por essas etapas.

Portanto, o subdesenvolvimento seria um problema de atraso econômico e ocorre porque existem obstáculos ao desenvolvimento que promovem círculos viciosos de pobreza que estancam o desenvolvimento (SINGER, 1977, p. 23). Um dos primeiros documentos estruturados sobre essa linha de pensamento é o livro The theory of economic development de Joseph A. Schumpeter.

Schumpeter (1983) cita que os principais obstáculos do desenvolvimento seriam: os atores de desenvolvimento, já que, no caso dos países subdesenvolvidos, o Estado tem um papel mais importante e não permite a mobilidade das empresas privadas;,métodos de produção, uma vez que apresentam a necessidade da utilização de novas tecnologias em detrimento da adaptação de técnicas antigas; a promoção do aumento do consumo e a diminuição do custo em matérias-primas (WALLICH, 1953 apud SINGER, 1964, p. 55).

Os defensores dessas teorias identificam que o problema estaria nos países subdesenvolvidos, nos quais predomina o setor rural, tradicional, superpovoado e de produtividade baixa, enquanto que nos países desenvolvidos predomina o setor industrial, moderno, com alta produtividade (LEWIS, 1955).

Entre os círculos viciosos da pobreza, poderíamos expressar como um dos mais conhecidos o apresentado no gráfico seguinte:

Gráfico 1: Circulo vicioso da pobreza

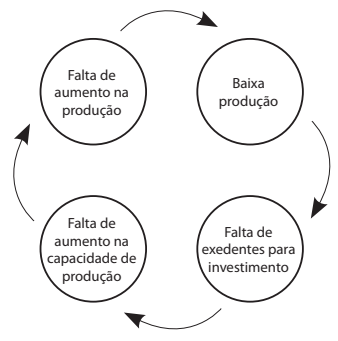

Fonte: Adaptação do documento SCHIAVO-CAMPO, Salvatore; SINGER, Hans W. Perspectivas de desarrollo económico. México: Fondo de Cultura Econômica, 1977, pág. 23. Tradução própria. 
Portanto, de forma geral, para obter desenvolvimento, considerando como essência o crescimento econômico, a solução seria uma réplica dos modelos europeu-americanos de industrialização, promover economia interna pelo endividamento, ajudas e/os investimentos estrangeiros e a intervenção estatal para o planejamento.

Especificamente, Higgins (1955 apud SINGER, 1977) comenta que o papel do ator de desenvolvimento seria o de "descobrir quais desses círculos são causa básica dos demais, quais podem se romper com maior facilidade e quais podem passar a ser mecanismos de retroalimentação que contribuam com o crescimento econômico sustentável”.

\subsubsection{Teoria estruturalista}

A Teoria Estruturalista do desenvolvimento considera também a modernização e a intervenção estatal. No entanto, incorpora fatores estruturais, nega a importância do comércio para o avanço do Sul e trata de explicar o desenvolvimento e subdesenvolvimento na escala mundial.

Baseia-se no Modelo Centro-Periferia, pelo qual se caracteriza o Centro como as economias de estrutura produtiva diversificada, homogênea e de produção e exportação de manufaturas, enquanto que a Periferia, como economias com estrutura produtiva especializada em número limitado de bens, níveis de produtividade heterogêneos e produção e exportação de produtos primários.

Essas diferenças criaram relações comerciais que reforçam o subdesenvolvimento, e o livre comércio acentuaria as desigualdades. Além do mais, haveria obstáculos para a periferia que dificultariam o desenvolvimento: trabalho (mano de obra), terra (produtividade agrícola), capital (economia e acumulação de capital) e estruturas sociais (desigualdades e tensões).

Portanto, para a Teoria Estruturalista, o subdesenvolvimento existe porque as relações comerciais Centro-Periferia e os obstáculos ao desenvolvimento reforçam as diferencias internacionais. 


\subsubsection{Teoria neomarxista}

Para os neomarxistas, o subdesenvolvimento é produto histórico do colonialismo e do imperialismo, um processo de contínua extração do excedente produtivo gerado na periferia, que foi transferido aos países-centro, promovendo uma baixa acumulação de capital, relações comerciais desiguais e bloqueio ao desenvolvimento da periferia. Esse contexto se acentuaria com os monopólios industriais e classes dominantes da periferia que não estariam interessados no desenvolvimento produtivo periférico e promoveriam um constante fluxo de recursos para o centro, tirando-as da periferia. A dependência promovida pelas relações econômicas internacionais também seria outro fator de bloqueio para o desenvolvimento. Por isso, negam a possibilidade de desenvolvimento e crescimento econômico sustentável para os países do Sul.

A solução seria a mudança político radical (revolução anticapitalista e a construção do socialismo) e a ruptura com o mercado capitalista mundial (desconexão). Consideram que se não é dessa forma, essas economias ficariam estancadas, ou seja, essa corrente tem uma visão pessimista de que o desenvolvimento da periferia não seria possível no ordenamento internacional existente na atualidade.

\subsubsection{Teoria da dependência}

A Teoria da Dependência surge na América Latina para alimentar as decisões enquanto o conceito de subdesenvolvimento, em um período no qual reinava a ideia das causas do subdesenvolvimento como meramente doméstico.

Alguns dos precursores mais conhecidos dessa corrente são o ex-presidente do Brasil Fernando Henrique Cardoso, que, em conjunto com Enzo Faletto, publicou o livro "Dependência e Desenvolvimento na América Latina”, entre vários outros autores.

Geralmente os autores que contribuíram para essa corrente tiveram bases marxistas e neomarxistas e trouxeram contribuições importantes para a evolução histórica do conceito de desenvolvimento, ao apresentarem como obstáculos para 
o desenvolvimento a crescente interferência estrangeira nos meios de produção internos dos países do Sul.

Sofreram críticas, especialmente dos economistas neoliberais, de que não se poderia sustentar que o capitalismo seja a causa do subdesenvolvimento. O pensamento da dependência e suas críticas marcariam a agenda de debates das décadas seguintes.

\subsubsection{Teoria neoclássica}

Foi a teoria dominante durante os anos oitenta e noventa e tem como pilares o estímulo à participação plena no comércio internacional e a eficiência do mercado como alocação ótima de recursos, se as economias se especializam de acordo com suas vantagens comparativas. Com isso, criticam fortemente a intervenção estatal às atividades econômicas por ser geradora de distorções de mercado e as estratégias de industrialização, por substituição e importações. Tiveram especial base nas contribuições de Robert Solow à teoria econômica.

O subdesenvolvimento seria provocado pelas distorções dos preços de produtos e fatores produtivos gerados pelo intervencionismo estatal. Essas intervenções também seriam ineficazes, mais caras e contraproducentes. As proteções advindas da industrialização por substituição de importações também causariam problemas a esses países, uma vez que impediriam uma abertura à economia mundial e, portanto, incentivos de eficiência e competitividade no comércio internacional. Entendem que, apesar da existência de falhas de mercado, elas seriam menores que as provocados pelo Estado.

Baseado nisso, propõe como saídas para o desenvolvimento a liberalização interna, a diminuição da intervenção estatal no mercado e a liberalização externa, a promoção de uma participação plena no comércio internacional com abertura comercial e financeira e descarte das estratégias de industrialização por substituição de importações. Essas políticas favoreceriam a um livre mercado e o Estado só interviria para permitir o funcionamento do mercado, mantendo os equilíbrios 
macroeconômicos, o entorno competitivo das empresas, o investimento público e o desenvolvimento institucional.

Foram tomadas em conta no período em que muitos países que aplicaram essa política de abertura de mercado cresceram mais economicamente. $\mathrm{O}$ domínio dessa teoria nas décadas de oitenta e noventa influenciou nas ideias e programas políticos dos principais organismos internacionais com o chamado Consenso de Washington.

\subsubsection{Principais críticas as teorias tradicionais de desenvolvimento}

Tomamos como teorias tradicionais as da modernização, as estruturalistas, as marxistas e as neoclássicas, que possuem em comum a ideia do desenvolvimento como crescimento econômico, ao qual o enriquecimento (econômico) se torna palavra chave quando se fala de desenvolvimento nessas teorias, deixando em segundo plano outros critérios como cultura, etnia, liberdades individuais etc. Essas teorias tradicionais sofrem forte crítica por estarem baseadas unicamente no crescimento econômico e deixando em segundo plano outros critérios como cultura, etnia, liberdade etc.

Grande parte desses teóricos apresenta a modernização econômica como algo positivo e o tradicionalismo como negativo, com uma clara desatenção à agricultura e outros setores tradicionais. Dão ênfase desmesuradamente à acumulação de capital físico, sem ter em conta o capital humano. Reconhecem explicitamente que poderia ser necessária a distribuição desigual de renda para o aumento de economia interno e assim fomentar investimentos.

Outro debate nas teorias tradicionais foi referentemente a confiança excessiva (modernização, estruturalismo) ou desconfiança (neoclássica) na intervenção do Estado em detrimento da ação livre ou limitada do mercado.

A teoria marxista questiona, entre outras, a negação do poder reformador do sistema, uma vez que não aceita a pluralidade de interesses em detrimento dos interesses convergentes entre os governos nacionais e as corporações multinacionais. 


\subsection{Teorias alternativas do desenvolvimento}

Nos anos setenta, percebia-se que as políticas de crescimento econômico levadas a cabo em vários países não surtiam o efeito desejado quando nos referimos às necessidades básicas da população.

Surgem em oposição/complemento às teorias tradicionais e ao "desenvolvimento como crescimento econômico", várias teorias, maiormente conhecidas como teorias alternativas do desenvolvimento, que expressam a necessidade de ampliar o conceito de desenvolvimento às esferas mais humanas e sociais, tratando as necessidades individuais e as características do coletivo humano como fatores centrais. Agora, o desenvolvimento seria tratado, pelos autores incluídos nessa tendência como transformação da realidade social e satisfação das necessidades básicas do ser humano.

O primeiro documento uniforme sobre esse novo conceito de desenvolvimento foi o livro Another Development: approaches and strategies (NERFIN, 1977) que, naquele momento, buscando opções de desenvolvimento mais coerentes a realidade local dos países do Sul, expressa que o outro desenvolvimento seria:

Orientado segundo as necessidades: satisfação de necessidades humanas tanto materiais como não materiais (necessidade de expressão, de criatividade, de igualdade, de convivência e de compreensão para edirigir seu próprio destino);

Endógeno: que saia do coração de cada sociedade, com seus próprios valores e visão de futuro;

Autossuficiente: que se baseia em defender que cada sociedade deveria valorizar suas próprias forças e recursos, energias de seus membros e seu meio ambiente natural e cultural;

Ecologicamente solvente: utilização racional dos recursos da biosfera, consciência do potencial dos ecossistemas locais e globais; e

Baseado em transformações estruturais: requisito nas relações sociais, econômicas e espaciais para a autoadministração e a participação, sem as quais as metas de cima não poderiam ser alcançadas. 


\subsubsection{Teoria do desenvolvimento humano}

Entre as teorias que surgiram como alternativas às tradicionais, se poderia dizer que uma das mais destacadas em sua implementação e utilização no âmbito internacional é a Teoria do Desenvolvimento Humano.

Essa teoria cresceu cimentada no enfoque das necessidades humanas e as contribuições de Amartya Sen (2000), que em suas publicações dá importância à defesa das liberdades inerentes ao ser humano, com especial foco às oportunidades econômicas, liberdades políticas, serviços sociais, garantias de transparência e segurança protetora.

Em 1990, o Programa das Nações Unidas para o Desenvolvimento (PNUD) publicou um Informe no qual apresentou suas aportações ao paradigma do Desenvolvimento Humano. Naquele momento também publicou o chamado Índice de Desenvolvimento Humano, conjunto de indicadores que agrupam não somente o poder aquisitivo (PIB per capita), anteriormente destacado de forma exclusiva, senão que também aspectos como Saúde (esperança de vida) e Educação (taxa de alfabetização e de matrícula).

\subsubsection{Gênero e desenvolvimento}

Muitas vezes a escola feminista tem uma tendência de ser vista como um escopo de análise limitado e singular ao âmbito de estudo das mulheres (womens studies). Podemos dizer que o feminismo sim posiciona o tema gênero como uma característica significante na interação com outras características, como raça (African-American/ethnic feminism) ou classe (socialist feminism), para estruturar relações entre indivíduos em um grupo em específico ou na sociedade em geral. No entanto, usa essa perspectiva de gênero para ver o mundo de diversas outras formas, criando diversas novas tendências teóricas: liberal feminism, postcolonial feminism (mudanças histórico-culturais), cyberfeminism (mudanças tecnológicas), postmodern feminism, radical feminism, entre outros (NICHOLSON, 1997; TONG, 1998 apud VALCARCEL, 2006). 


\subsection{Outras teorias alternativas do desenvolvimento}

Michael Todazo (1982) também agregou sua contribuição, apresentando sua interpretação multidimensional do fenômeno do desenvolvimento e subdesenvolvimento. O Desenvolvimento Multidimensional supôs um conjunto de transformações do sistema social para alcançar que as condições de vida materiais e imateriais sejam melhores que antes. Para isso, utiliza um análise de efeitos circulares entre dimensões distintas e interdisciplinares.

Tendo em conta essa polarização e multidimensão do desenvolvimento, poderíamos imaginar tentativamente um gráfico de inter-relação entre os critérios político, social e econômico:

Gráfico 2: Círculos viciosos e virtuosos do desenvolvimento econômico.

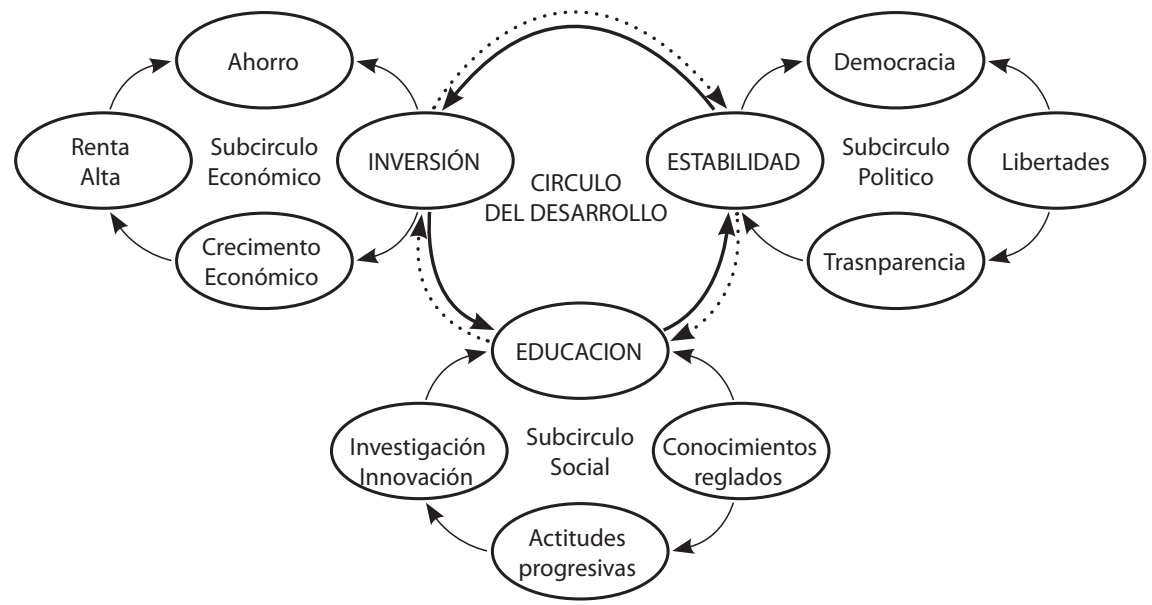

Fonte: FONTELA, E. et GUZMÁN, J. Círculos viciosos y virtuosos del desarrollo económico. Estudios de Economía Aplicada. v. 21, p. 234, 2003.

O Endodesenvolvimento é outro modelo que destaca o papel central das comunidades afetadas, enfatizando seus recursos naturais e humanos e seus valores culturais. Dentro dessa visão, surgem os conceitos de Desenvolvimento Endógeno, que buscaria valorizar o papel do território na estratégia de desenvolvimento, e Etnodesenvolvimento, que põe em destaque os valores éticos e culturais da comunidade a qual vai dirigida a ajuda. 
Outras correntes trabalham com o desenvolvimento, preocupando-se enfaticamente com o meio ambiente. Entre essas estaria o Ecodesenvolvimento, pelo qual se enfatizam os problemas particulares de cada região a partir dos dados culturais e ecológicos, referindo-se à cultura como um recurso de valor incalculável que "tiene hoy una reducida oferta, están disminuyendo rápidamente y no son renovables" (SACHS, 1974, p. 81). Para defender esse recurso nos dias atuais, seria opção o acesso "a una mayor cantidad de los frutos de las sociedades industriales sin intentar industrializar al mundo entero" (SACHS, 1974, p. 81).

Na linha de pensamento da proteção ambiental surge também o já conhecido e estendido conceito de Desenvolvimento Sustentável, o qual buscaria satisfazer as necessidades do presente sem afetar as capacidades das gerações futuras de satisfazer suas próprias necessidades. Esse conceito surgiu com maior força no cenário internacional na Conferencia das Nações Unidas sobre Meio Ambiente e Desenvolvimento (Rio-92).

No fim dos anos 90, surge uma corrente mais radical conhecida como Pós-Desenvolvimento (Postdevelopment Theory) que critica as teorias neste âmbito, afirmando que o conceito de desenvolvimento seria um instrumento de dominação e hegemonia do Ocidente/Norte e estariam carregadas de um discurso de poder e de controle social dos povos que primariam as ideias dos países economicamente desenvolvidos de como o mundo deveria ser.

\section{Conclusão}

O conceito de desenvolvimento tem sofrido constantes mudanças e releituras e possui ampla literatura sobre o tema, de acordo com o momento histórico e sua aplicação marcada em sua grande parte pelas influências das nações mais poderosas. $\mathrm{Na}$ atualidade, vem ocupando posição importante nas ciências sociais nos países desenvolvidos e menos desenvolvidos e, especificamente, na América Latina, ressurge no marco da oposição entre as políticas de desenvolvimento que prezam o fator humano e ambiental e o domínio do capital financeiro. 
Podemos observar que, de forma relativa, as teorias no campo conceitual têm alcançado importantes conquistas, porém ainda carecem de resultados empíricos relevantes.

Um exemplo da importância do conceito do desenvolvimento na cooperação internacional se demonstra, por exemplo, com a recente mudança do nome da principal agência pública espanhola de cooperação internacional, a Agencia Española de Cooperación Internacional (AECI), para Agencia Española de Cooperación Internacional para el Desarrollo (AECID), dando não somente ênfase ao termo desenvolvimento, mas também destacando o amplo âmbito de atuação, a cooperação para o desenvolvimento, como têm feito anteriormente outras agências internacionais como CIDA (Canadá), SIDA (Suécia), UK DFID (Reino Unido), entre outras.

A cooperação internacional pode ser um importante instrumento catalisador da prática do desenvolvimento no âmbito das relações internacionais e, em termos teóricos e conceituais, busca acompanhar as evoluções do conceito de desenvolvimento. No entanto, algumas vezes dista desta na prática quando se depara com os diversos obstáculos que sofrem frente a influências de interesses no nível político, econômico e ideológico, inseridos na complexidade do ciclo de políticas e de seus processos decisórios complexos e burocráticos.

Uma importante superação desses obstáculos pode ser a promoção de alianças e suficiente coordenação e colaboração entre as partes envolvidas no setor de atuação, além da redução das diversas formas de condicionalidades da ajuda, das turbulências na efetivação do financiamento para o desenvolvimento, entre outros aspectos que formam parte da prática da cooperação ao desenvolvimento.

Portanto, adaptar os avanços do conceito de desenvolvimento que vejam mais além do crescimento econômico e favoreçam a valorização de fatores como cultura e meio ambiente se torna um dos desafios importantes das relações internacionais e, especificamente,da prática da cooperação internacional. 


\section{Development theories and the international cooperation}

\section{Abstract}

This paper aims to address in a didactic way the issue of development and evolution of this concept, considering the main theoretical trends, including traditional theories of modernization, structuralism, neo-Marxist, dependency, neoclassical, as well as an introduction to alternative theories of development, as the Theory of Human Development, Gender and Development, Multidimensional development, Endogenous Development, Eco-development and Post-development. The study concludes with comments on the application of this concept in the framework of international cooperation activities.

Keywords: Development. Development theories. International cooperation, International relations. Economic development. Development policies.

\section{Referências}

BOBBIO, Norberto. Dicionário de política. Brasília: Universidade de Brasília, 2002.

BONFIGLIOLI, A. Empowering the poor: local governance for poverty reduction. New Yok: United Nations Capital Development Fund, 2003.

CERRILLO, Agustí. La cooperación al desarrollo y el fomento de la gobernabilidad. Revista Instituciones y Desarrollo, Barcelona, n. 8, v. 9, p. 543-576, 2001.

DUBOIS, Alfonso. Cooperación para el desarrollo. Hegoa Diccionario de Acción Humanitaria y Cooperación al Desarrollo. Disponível em: < http://dicc.hegoa. efaber.net/listar/mostrar/44>. Acesso em: 11 de novembro de 2009.

FONTELA, E.; GUZMÁN, J. Círculos viciosos y virtuosos del desarrollo económico. Estudios de Economía Aplicada. [S.1], v. 21-2, p. 221-242, 2003.

GARCÍA LIZANA, Antonio et. al. Planificación estratégica sostenible de redes territorial: teoría y práctica. Málaga: Universidad de Málaga, 2005.

HAQUE, M. Shamsul. Restructuring development theories and policies. [S.1]: SUNY Press, 1999. 
LEWIS, William Arthur. The theory of economic growth. [S.l:s.n], 1955.

LIMA, Luciano Barbosa de. Cooperação para o desenvolvimento no contexto de crises, conflitos e catástrofes. Trabalho de conclusão de curso (Graduação)Faculdade de Relações Internacionais, Centro Universitário de Brasília, Brasília, 2005.

LIMA, Luciano Barbosa de. Posibilidades de cooperación España-Brasil en materia de administración pública local: el caso del Norte y Nordeste de Brasil. Málaga: Universidad de Málaga, 2008.

NERFIN, Marc (Ed.). Another development: approaches and strategies. Uppsala: Dag Hammarskjöld Foundation, 1977.

OECD. Shaping the 21st century: the contribution of development co-operation. Paris: Development Assistance Committee, 1996.

PNUD. Informe sobre desarrollo humano 2007-2008. New York: PNUD, 2007.

ROSSER, Sue V.; MILLER, Patricia H. Viewing developmental psychology through the lenses of feminist theories. Anuário de Psicologia, Barcelona, v. 34, n. 2, p. 291303, 2003.

SACHS, Ignacy. Enfoques de la política del medio ambiente. Economía del medio ambiente. Madrid: Instituto de Estudios Fiscales, 1974.

SCHIAVO-CAMPO, Salvatore; SINGER, Hans W. Perspectivas de desarrollo económico. Traducción de Jorge Ferreira Santana. México: Fondo de Cultura Económica, 1977.

SCHUMPETER, Joseph A. The theory of economic development: an inquiry into profits, capital, credit, interest, and the business cycle. [S.I]: Oxford University, 1983.

SEN, Amartya. Desarrollo y libertad. Traducción de Esther Rabasco y Luis Toharia. Barcelona: Planeta, 2000.

SINGER, H.W. International development: growth and change. New York: McGrawHill Book Company, 1964.

SINGER, H.W. Perspectivas de desarrollo económico. México: Fondo de Cultura Económico, 1977. 
90 | Univ. Rel. Int., Brasília, v. 8, n. 1, p. 73-90, jan./jun. 2010
Luciano Barbosa de Lima

TODARO, Michael P. Economía para un mundo en desarrollo: introducción a los principios, problemas y políticas para el desarrollo. México: Fondo de Cultura Económica, 1982.

UNESCO. Instituto de Estudios Políticos. Diccionario de ciencias sociales. Madrid: [s.n.], 1975.

VALCÁRCEL, Marcel. Génesis y evolución del concepto y enfoques sobre el desarrollo: documento de investigación. Lima: PUC, 2006. 